\title{
El tardío reconocimiento del carácter mercantil de las sociedades cooperativas y su consecuencia
}

\author{
Antonio José Macías Ruano \\ Doctor en Derecho \\ Universidad de Almería. Centro Universitario Adscrito de Trabajo Social
}

Sumario: 1. Estado de la cuestión en materia de política legislativa de cooperativas en España. 2. La Cooperativa como sociedad mercantil. 2.1. Hasta el Código de Comercio de 1885. 2.2. Desde la publicación del Código de Comercio de 1885. 2.3. Desde la publicación del DecretoLey de Cooperativas de 4 de julio de 1931 y la Ley del Gobierno Militar de 1942. 2.4. Desde la publicación de la Ley General de Cooperativas de 1974. 2.5. Publicación de la Constitución Española de 1978 y la delimitación de competencias entre el Estado y las Comunidades Autónomas. 2.6. Desde la publicación de la Ley General de Cooperativas de 1987. 2.7. Desde la publicación de la Ley (estatal) de Cooperativas de 1999.

3. Referencias bibliográficas.

Resumen: La dispersión normativa en materia de sociedades cooperativas es el efecto de circunstancias históricas y políticas que van más allá de la sentencia del Tribunal Constitucional de 1983 asumiendo la constitucionalidad de la Ley 1/1982, de 1 de febrero, sobre Cooperativas, del País Vasco, a la que siguieron otras de diversas comunidades autónomas hasta el actual marco legal cooperativo. El que no se hubiera asumido por el legislador nacional antes de 1979, fecha de publicación del primer estatuto de autonomía, la naturaleza mercantil de las sociedades cooperativas ha dado lugar a esta situación, sin embargo, el debate y conclusiones del carácter mercantil de las sociedades cooperativas ha estado presente en la doctrina desde mucho antes de dicha fecha. En este trabajo se hace un repaso a las concepciones y justificaciones legales que se ha dado a las cooperativas hasta su actual percepción como sociedades de naturaleza mercantil.

Palabras clave: Sociedades Cooperativas, naturaleza mercantil, competencia legislativa.

Abstract: The wide range of legislation existing on cooperative societies is the result of historical and political circumstances that go beyond the de- 
cision of the Constitutional Court of 1983 accepting the constitutionality of Act 1/1982, of 1 February, on Cooperatives, of the Basque Country, which was followed by others from other autonomous communities until the current legal cooperative framework was reached. This stemmed from the fact that the commercial nature of cooperative societies had not been accepted by the national legislator before 1979, when the first Statute of Autonomy was published. However, the discussions and conclusions on the commercial nature of cooperative societies have been present in the legal doctrine far before that date. This paper briefly reviews the legal concepts and grounds that have been provided with regard to cooperatives through to their current perceived status as commercial societies. tence.

Keywords: Cooperative Societies, commercial nature, legislative compe- 


\section{Estado de la cuestión en materia de política legislativa de cooperativas en España}

El marco legislativo de las cooperativas en España es harto complejo. Existe una Ley sustantiva de ámbito nacional — que se aplica en Ceuta, Melilla y, por ahora en la Comunidad Canaria, y para aquellas cooperativas que tienen un ámbito territorial de actuación disperso en varias comunidades autónomas, es decir, de muy escasa aplicación práctica-; dieciséis leyes autonómicas sustantivas, algunas con reglamentos propios; algunas comunidades regulan, además, cooperativas especiales - pequeñas cooperativas-; una Ley nacional para las cooperativas de crédito; una Ley que regula la sociedad cooperativa europea; una Ley de ámbito nacional que regula el régimen fiscal cooperativo; normativa de ámbito nacional en materia de contabilidad; diversas normativas autonómicas para regular los registros territoriales de cooperativas; más normas para regular las entidades públicas o semipúblicas de promoción cooperativa; etcétera, etcétera, etcétera. La dispersión legislativa nacional en España, como ha coincidido toda la doctrina patria, supone un problema de eficiencia de una estructura societaria que tiene un marco jurídico distinto en cada Comunidad Autónoma del Estado, cuando tiene que competir en un mercado cada vez más amplio y global. El panorama nacional como resalta, por todos, GARCíA JIMÉNEZ, es "sin duda, desolador, plagado de inseguridad jurídica, que lejos de fomentar el cooperativismo, se está convirtiendo en un obstáculo. Una legislación dispersa e inconexa, que bajo impulsos de quién es el primero o más original, está llevando al abandono de principios esenciales, de los que el legislador no puede disponer, en pos de unos supuestos intereses superiores empresariales o de mercado» ${ }^{1}$. Se ha

1 GARCÍA JIMÉNEZ, «La necesaria armonización internacional del Derecho Cooperativo: el caso Español», REVESCO, N. ${ }^{\circ} 102$, Madrid, 2010, p. 84. Quizá más contundente, aún, sea el comentario que hace ALONSO ESPINOSA, quien afirma que «La cooperativa es una forma de sociedad bastante desgraciada desde el punto de vista de su regulación legal... ha convertido la regulación de la cooperativa en un complicado, absurdo $y$, con frecuencia, disfuncional e inseguro laberinto, creando un panorama legislativo único en el mundo», en el "Prólogo» de la obra colectiva La Sociedad Cooperativa en la ley 27/1999, de 16 de julio, de Cooperativas, AA.VV., coordinado por el mismo autor, Edit. Comares, Granada, p. XXV. Y aún más radical puede ser el comentario que hace LLOBREGAT HURTADO quien afirma que «se puede cuestionar a estas alturas la inconstitucionalidad de la leyes autonómicas por tratarse de legislación mercantil reservada al Estado en el artículo 149 de nuestra Constitución», en "Régimen económico de las sociedades cooperativas», RdS., n. ${ }^{\circ} 13$, Madrid 1999-2, p. 13; y, por señalar otro autor, PANIAGUA ZURERA sumándose a las palabras de CHULIÁ, señala que nuestro marco normativo en materia de cooperativas es «un auténtico despropósito legislativo, que es 
consagrado la desigualdad de los ciudadanos en el territorio nacional a la hora de elegir una estructura societaria para el desarrollo de una actividad económica y profesional, puesto que, en función de dónde señalen los emprendedores (socios cooperativistas) que sea el ámbito principal de desarrollo de su actividad social, deberán inscribir su sociedad, y adaptar su estructura y estatutos al correspondiente marco normativo del domicilio social.

Esta situación legislativa nacional tiene diversas causas, una de ellas es el hecho de que la unidad legislativa en España no se ha dado prácticamente nunca. De hecho, desde el fallecimiento de Carlos II, y tras la Guerra de Sucesión y la llegada al trono de Felipe $V$ se pretende imponer en España una nueva organización política, administrativa y legislativa de carácter centralista. La paulatina imposición de los Decretos de Nueva Planta, de abolición de fueros particulares, fue inexorable, pero, sin embargo, concedió la "gracia» de mantener los fueros de navarros y vascuences. Esta situación jurídica se mantuvo hasta la Constitución de Bayona de 1808, donde el centralismo se impone en toda la nación, aunque salvando, por aplazamiento, los de las Provincias de Navarra, Álava, Guipúzcoa y Vizcaya². La Constitución de 1812 contempla todo el territorio nacional bajo un solo reino, el de España, resaltándose la unidad constitucional de todo el Estado. Con la llegada al poder de Fernando $\mathrm{VII}^{3}$, con el dictado del Decreto dado en Valencia el 4 de mayo

objeto de unánime crítica doctrinal, y que avanza... en dirección contraria a los objetivos y las directrices de la Unión Europea en materia de Derecho de sociedades», en "La sociedad-empresa cooperativa en la evolución de los modelos lus Cooperativos en España», RdS, n. ${ }^{\circ} 40$, enero-junio, 2013, p. 187. Y como última opinión doctrinal, por su contundencia, significar la de MORRILLAS JARILLO, quien afirma que sería «necesaria declaración de inconstitucionalidad de todas las leyes de cooperativas autonómicas», en su artículo "El ámbito de aplicación de las leyes de sociedades cooperativas», en «Derecho de sociedades. Libro Homenaje a Fernando Sánchez Calero. Vol. V», AA.VV., Edit. McGraw Hill, Madrid 2002, p. 4757.

2 El artículo 144 de la Constitución de Bayona, recogía, expresamente: «Los Fueros particulares de las provincias de Navarra, Vizcaya, Guipúzcoa y Álava se examinarán en las primeras Cortes, para determinar lo que se juzgue más conveniente al interés de las mismas provincias y de la nación». Un análisis histórico y pormenorizado del proceso de concreción de los fueros particulares de las Provincias Vascas y de Navarra, lo encontramos en el estudio realizado por MONREAL ZÍA, en «Los Fueros Vascos en la Junta de Bayona de 1808», en Revista Internacional de Estudios Vascos, cuaderno 4, 2009, pp. 255 a 276.

3 Ya en 1807, Fernando VII estuvo conspirando contra a su padre Carlos IV, pero fue descubierto y condenado en el Ilamado Proceso de El Escorial. Pidió clemencia y fue perdonado por su padre, y al año siguiente, encabezando el motín de Aranjuez, toma del poder derrocando al valido Godoy. Sin embargo Napoleón, mientras, invadió España, y apresó a Fernando, obligándolo a devolver a Carlos IV el poder para que éste pudiera abdicar en José I, hermano del emperador invasor. 
de 1814, se disuelven las Cortes Generales dejando de tener vigencia la Constitución de Cádiz de 1812, y se vuelve al Antiguo Régimen absolutista, con lo que se retoma la vigencia los fueros de Navarra, Álava, Guipúzcoa y Vizcaya. La vuelta con Riego al constitucionalismo, el llamado trienio liberal (1820 a 1823), implica, de hecho, la nueva pérdida de vigencia de los fueros navarro y de las provincias vascongadas. Pero la entrada de los Cien mil hijos de San Luís, en 1823, sofocó cualquier foco constitucionalista e implicó la vuelta al absolutismo con Fernando VII. A la muerte de Fernando VII, en 1833, su hermano Carlos disputa a la hija de aquel, Isabel, el trono dando lugar a las denominadas Guerras Carlistas. Con el Convenio de Vergara, de 31 de agosto de 1839, tras la rendición de las tropas carlistas que operaban, fundamentalmente en Navarra, Vascongadas y Cataluña, supuso, de hecho, el fin a la Primera Guerra Carlista. Posteriormente se promulgó la Ley de 25 de octubre de 1839, de confirmación (supresión) de fueros. Posteriormente, para Navarra, se publica la Ley Paccionada de 16 de agosto de 1841, que consigue, en gran medida, el mantenimiento de su Fuero propio, pero dejando, definitivamente de ser Reino, convirtiéndose en una provincia más en la unidad constitucional del Estado.

En el País Vasco no se dictó ninguna ley paccionada para recuperar su legislación foral. Sin embargo, la pérdida del fuero no supuso el de la autonomía tributaria, puesto que desde 1878, se fueron publicando distintos reales decretos de fijación y renovación del Concierto Económico entre el Estado y las Provincias Vascongadas.

Centrándonos en el ámbito de la variada legislación nacional en materia de cooperativas, desde la Segunda República, en el artículo 1 de la Constitución de 1931 se señalaba que "La República constituye un Estado integral, compatible con la autonomía de los Municipios y las Regiones», determinándose en el Título I el sistema de Organización Territorial, con la posibilidad de que distintas regiones históricas pudieran constituirse en régimen de autonomía —arts. 8 y 11 - y previéndose un reparto de competencias legislativas para esas regiones autónomas, en el que se reserva, con carácter de competencia exclusiva del Estado, la legislación en materia mercantil, aunque con posibilidad de ejecución de tal competencia a cargo de las regiones autónomas -art. 15-.

En el ámbito estatal, en 1931, se publica la primera Ley de Cooperativas específica. Y en el marco constitucional de la Segunda República Española, se publica, en la Gaceta de Madrid de 21 de septiembre de 1932, el primer Estatuto de Autonomía de Cataluña, tras el fallido Proyecto de 1919, donde se dispone, en su artículo 11, que "corresponden a la Generalidad de Cataluña la legislación exclusiva y la ejecución 
y dirección de las funciones siguientes: ....F) Cooperativas, Mutualidades y Pósitos, con la salvedad, respecto a las leyes sociales, hecha en el párrafo primero del artículo 11 de la Constitución».

Y en desarrollo de esta competencia exclusiva de la región catalana, el Parlamento de la Generalitat de Cataluña aprobó, el 17 de febrero de 1934, la Ley de Bases de la Cooperación para Cooperativas, Mutualidades y Sindicatos Agrícolas, y el 17 de marzo del mismo año, la Ley de Cooperativas de Cataluña. Con lo que, a nivel nacional, ya existían dos leyes de regulación de las cooperativas, una a nivel General para todo el Estado, la de 1931, y otra de ámbito autonómico regional, la Catalana de 1934.

Otro tanto sucede en relación con el Estatuto de Autonomía del País Vasco a finales de la Segunda República. En 1936, en la Gaceta de Madrid número 281, de 7 de octubre, ya iniciada la Guerra Civil, se publica el Estatuto del País Vasco, en cuyo artículo 2, apartado e) se asigna «la competencia del País Vasco, de acuerdo con los artículos 16 y 17 de la Constitución de la República, la legislación exclusiva y la ejecución directa en las materias siguientes:... Cooperativas, Mutualidades y Pósitos, con la salvedad respecto a las leyes sociales contenidas en el número $10^{\circ}$ del artículo 15 de la Constitución», pero no se produjo el desarrollo legislativo que sí se dio en Cataluña, debido a la continuación de la Guerra Civil.

Entre 1937 y 1938 se produjo, por el gobierno militar del General Franco, la derogación tanto del Estatuto de Cataluña ${ }^{4}$, como el del País Vasco ${ }^{5}$, así como toda norma de desarrollo de las competencias de aquella región autónoma.

El nuevo Gobierno militar publicó la Ley de Cooperativas de 1942, de ámbito estatal sin que hubiera otra disposición legislativa de distinto ámbito territorial.

Restaurada la democracia y aprobada la Constitución de 1978, se configura España como un Estado Autonómico, con distribución de competencias legislativas entre el propio Estado y las distintas Comunidades Autónomas (arts. 148 y 149). Con este nuevo marco legal, la unidad en la legislación nacional en materia de cooperativas podría estar legítima y definitivamente resuelta, dado que las sociedades cooperativas, como agentes económicos profesionales que intervienen en el mercado, como cualquier otro tipo de empresario, estarían comprendi-

4 Ley de 5 de abril de 1938.

5 Decreto-ley de 23 de junio de 1937, donde, además, se califican a las provincias de Vizcaya y Guipúzcoa como «traidoras», privándolas de concierto económico que históricamente venían disfrutando. 
das por la legislación en materia mercantil (art. 149.1 6. ${ }^{\circ}$ C.E.), lo que asignaría su regulación al ámbito estatal.

Pero, a raíz de la aprobación de la Ley Orgánica 3/1979, de 18 de diciembre, Estatuto de Autonomía del País Vasco, ley estatal por tanto, se fija, en su artículo 10.23, como competencia exclusiva de ésta Comunidad Autónoma, el desarrollo legislativo en materia de «Cooperativas, Mutualidades no integradas en la Seguridad Social y Pósitos conforme a la legislación general en materia mercantil», contraviniendo el legislador nacional el ámbito competencial constitucional.

En el desarrollo de esta competencia legislativa en materia de cooperativas asignada en el Estatuto de Autonomía del País Vasco, se promulgó la Ley 1/1982, de 1 de febrero, sobre Cooperativas, que resultó, como era natural, una ley sustantiva de regulación de las sociedades cooperativas en el ámbito de esta Comunidad Autónoma. Esta norma fue recurrida ante el Tribunal Constitucional por el Gobierno de la Nación en dos artículos (arts. 3 y 8) y la disposición final primera, entendiendo que las competencias en materia de legislación mercantil le correspondía con carácter de exclusividad al Estado conforme a lo dispuesto en el artículo 149.1.6. ${ }^{\circ} \mathrm{CE}$, por resultar esta figura jurídica materia propia de la legislación mercantil, y por tanto, la regulación sustantiva que se presentaba en la Ley Vasca estaba fuera de sus competencias, asumiendo, sin embargo, el resto del texto normativo sustantivo, quizá como argumento político que admite su regulación total, introduciendo conceptos jurídicos absolutos y de base para un recurso nimio basado en una eficacia extraterritorial de la norma autonómica y la formalidad del contrato de constitución. El Tribunal Constitucional, nacido con la LO 2/1979, de 3 de octubre, dictó la sentencia n. ${ }^{\circ} 72 / 1983$, de 29 de julio ${ }^{6}$, en la que, en definitiva, venía a considerar que dado que en la Constitución Española no se habla de forma explícita de las cooperativas como objeto de asignación de competencias exclusivas del Estado7, y dado que la Ley Orgánica del Estatuto Vasco, norma, por tanto, de ámbito estatal, sí contemplaba tal asignación como competencia exclusiva de la Comunidad, en base a lo previsto en

6 Calificada por ALONSO ESPINOSA, como «desgraciada» por la pérdida de la oportunidad que el Tribunal Constitucional tuvo para poner en orden el Régimen Jurídico de las cooperativas, en el «Prólogo», op. cit. 2001, p. XXVII.

7 El texto del fundamento jurídico de la STC 72/1983 es que «la Constitución no reserva de modo directo y expreso competencia alguna al Estado en materia de cooperativas y, en consecuencia, de acuerdo con el art. 149.3 de la propia Norma, la Comunidad tiene las competencias que haya asumido en su Estatuto, correspondiendo al Estado las no asumidas.». 
el apartado 3 del mismo artículo 149 CE, en el que se señala que «Las materias no atribuidas expresamente al Estado por esta Constitución podrán corresponder a las Comunidades Autónomas en virtud de sus respectivos Estatutos», el Tribunal Constitucional, sin entrar en valorar si las cooperativas pudieran resultar una tipología societaria del ámbito mercantil, con una respuesta quizá más política que jurídica ${ }^{8}$, dio carta de naturaleza a la legislación autonómica sobre la materia, permitiendo la legislación sustantiva autonómica de esta estructura societaria. Seguidamente, los estatutos de Cataluña, de Andalucía, de Valencia y de Navarra, que recogían igualmente las competencias exclusivas en materia cooperativa, posibilitaron la publicación de sus correspondientes leyes sustantivas de regulación de las cooperativas en su ámbito territorial. Con este mapa de competencias legislativas autonómico en materia de cooperativas, el Parlamento de la nación, por Ley Orgánica 9/1992, de 23 de diciembre, de Transferencia de competencias a Comunidades Autónomas que accedieron a la autonomía por la vía del artículo 143 de la Constitución, traspasó a todas las comunidades autónomas las competencias legislativas en materia de cooperativas, con lo que se ha consagrado la dispersión normativa en materia de cooperativas en el Estado.

Posiblemente el actual panorama legislativo nacional en materia de cooperativas sería distinto y estaría unificado si se hubiera determinado con precisión el carácter mercantil de las sociedades cooperativas antes de la aprobación por las Cortes Generales la Ley Orgánica 3/1979, de 18 de diciembre, Estatuto de Autonomía del País Vasco, dada a atribución al Estado de la competencia exclusiva en materia mercantil (art. 149.1.6. ${ }^{\circ}$ C.E.). Y tanto el legislador de 1979 como el Tribunal Constitucional pistas para tal concepción había antes de la aprobación de la norma, y así se ha ido conceptuando con posterioridad.

8 El Tribunal Constitucional afirma respecto a las cooperativas que se «prescinde de cualquier posición doctrinal acerca de si las cooperativas han de calificarse o no como sociedades mercantiles, ya que la interpretación ha de situarse en el contexto del ordenamiento vigente». Con tales afirmaciones, PANIAGUA ZURERA califica a esta Sentencia del Tribunal Constitucional, como «temprana y torpe», que abre la espita a una injustificable y perjudicial "fecundidad legislativa» en España, siendo dictada "con evidente miopía económica y jurídica», puesto que "ha admitido la regulación autonómica de todo el régimen jurídico-privado de las sociedades-empresas cooperativas para su respectivo territorio», afirmando, finalmente, que "el Tribunal Constitucional no ha actuado como máximo garante de la superioridad material de nuestra Norma Fundamental: nos referimos al reparto de competencias normativas sobre cooperativas entre el Estado y las Autonomías» en "La sociedad-empresa cooperativa...», op. cit. 2013, pp. 186 y 198. 


\section{La Cooperativa como sociedad de naturaleza mercantil}

Cuestión altamente debatida por la doctrina, determinada la naturaleza societaria de la cooperativa, es si ésta tiene o no carácter mercantil. Con carácter general, la determinación de la naturaleza civil o mercantil de una sociedad hay que buscarla en el cómo se obtenga el beneficio del socio, y cuál sea este atendiendo a los criterios de mercantilidad que establecen los códigos civil (art. 1.670) y mercantil (art. 116), o las distintas leyes especiales reguladoras de distintas tipologías societarias, y cuya calificación será la que distinga la aplicación de un Régimen Jurídico u otro. Si el beneficio económico se pretende de una actividad económica y profesional, el contrato asociativo será el de una sociedad de carácter mercantil (con base a los criterios de mercantilidad previstos en el artículo 1.670 Cc). En cambio, si lo que se pretende y persigue es un beneficio al margen de una actividad económica profesional, podremos estar ante una sociedad civil o una asociación, salvo que su régimen jurídico específico señale una naturaleza mercantil o civil en base a su forma, como sucede con las sociedades agrarias de transformación (art. 1.1 RD 1776/1981, de 3 de agosto, por el que se aprueba el Estatuto que regula las Sociedades Agrarias de Transformación).

En el estricto ámbito mercantil, se establece una división muy nítida entre las sociedades denominadas personalistas y las capitalistas $^{9}$ en

9 En la doctrina se ha desarrollado una gran cantidad de criterios de clasificación de las sociedades mercantiles, más o menos utilizadas y reiteradas, así, y como ejemplo, LANGLE hace un extenso desarrollo de las posibles clasificaciones de las sociedades mercantiles («comerciales») que pueden darse atendiendo a un «criterio económico o jurídico y, dentro de este último, el teórico o el legal. También es dado a separarlas por razón de la clase de responsabilidad que contraen sus socios, por el predominante carácter personalista o capitalista, por la manera cómo se divide o representa el capital social, por la índole de las operaciones que realizan, por el principal interés que satisfacen, por la clase de personas que las componen, etc.», desarrollando, entre otras, la clasificación de sociedades de personas y de capital en "Manual de Derecho Mercantil Españo/», Tomo I, Edit. Bosch, Barcelona, 1950, pp. 454-457. En cambio GARRIGUES pone el acento en la clasificación de las sociedades en «el criterio que clasifica las sociedades por el dato de la distinta responsabilidad del socio por las deudas sociales», en "Instituciones de Derecho Mercantil», Madrid,1943, p. 78. Y GIRÓN, fundamenta el criterio de clasificación esencial de las sociedades mercantiles en «la manera en que se produce en estos contratos la concatenación de las obligaciones de los contratantes y su efecto organizador», lo que le lleva a dividir a las sociedades como "de personas» o "de capitales», en "Derecho de Sociedades. Tomo /», Madrid, 1976, pp. 138-143. En cualquier caso, a la hora de abordar cada una de las denominadas sociedades mercantiles tipo (enunciadas en el art. 122 C. de c.), toda la doctrina caracteriza a las colectivas y comanditarias simples de sociedades de base personalista, y a las comanditarias por acciones, limitadas y anónimas, como de base capitalista. 
base al papel que juega el elemento subjetivo del contrato de sociedad, esto es el socio. En las personalistas, la razón que justifica la prestación del consentimiento del socio para constitución de la sociedad y la continuidad de la actividad societaria son los demás socios que la suscriben. Son sociedades cerradas, donde no se podrá incorporar un socio nuevo si no es con el consentimiento de todos los socios actuales (art. 143 C. de c.). En cambio, en las sociedades capitalistas, el elemento esencial para la constitución y desarrollo de la sociedad es el capital invertido, donde la transmisión de la condición de socio está más o menos garantizada, puesto que el socio no es la medida del desarrollo de la actividad societaria, sino el capital invertido en ella.

Y, entre las denominadas sociedades capitalistas, si la obtención del beneficio por el socio es proporcional a la inversión que éste haga en el capital social o fondo común, estaremos ante sociedades mercantiles de carácter capitalista convencional. Si, en cambio el beneficio se persiguiera por medio de la realización de la actividad por el socio, con una concepción puramente instrumental de la sociedad para éste, la sociedad cooperativa, que necesita la aportación obligatoria de capital por el socio, se calificaría capitalistas pero propia de la economía social. En otro nivel de análisis societario de las empresas de economía social, habría que distinguir aquellas empresas que potencian, esencialmente, el beneficio de sus socios, o las que potencian el beneficio del entorno social - estaríamos en la categoría de la economía social, aunque en esta clasificación de sociedades también cabrían cualquier tipología social que pretendiera el desarrollo del entorno social, búsqueda de empleos dignos, la igualdad de género, el desarrollo de servicios sociales, etc.- .

El gran obstáculo para la consideración o no de las cooperativas como sociedades mercantiles, como señala CARRERAS ROIG, es «el ánimo de lucro, requisito tradicionalmente ligado a las sociedades y extraño o pretendidamente incompatible con las sociedades cooperativas» ${ }^{10}$. Aunque el término lucro no significa más que «Ganancia o provecho que se saca de algo» ${ }^{11}$, con lo cual, consustancial al contrato de sociedad es la obtención de lucro (art. 116 C. de C - para obtener lucro-y 1665 Cc. —ánimo de partir entre sí las ganancias-).

Sin pretender un análisis histórico exhaustivo del régimen jurídico de las cooperativas en España, vamos a seguir el mismo criterio que

10 Vid. CARRERAS ROIG, en «Consideraciones en torno al posible carácter mercantil de las sociedades cooperativas y acerca de las limitaciones a la realización de operaciones con terceros no socios de estas entidades», REVESCO, n. ${ }^{\circ} 106$, Tercer Cuatrimestre 2011, p. 57.

11 Primera acepción de la palabra lucro según la RAE. 
GÓMEZ CALERO ${ }^{12}$ hace en torno al tratamiento legal de las cooperativas en España, para su posible calificación como sociedades mercantiles, diferenciando distintas etapas legislativas.

\subsection{Hasta el Código de Comercio de 1885}

Desde la publicación del Decreto de 19 de octubre de $1868^{13}$ —primera norma legal positiva española que nombra a las cooperativas, aprobada en el denominado Sexenio Democrático a raíz de la Revolución de septiembre de 1869 - , hasta la publicación del Código de Comercio de 1885, las distintas disposiciones legales que se fueron publicando contemplaban a las cooperativas al margen de su posible o no mercantilidad, ignorando tal extremo, preocupándose, solo, del aspecto formal de su constitución y publicidad económica.

La Ley de sociedades anónimas de 1869, con su referencia a las cooperativas, hace que el cooperativismo legislativo nazca de las ideas de libertad de asociación y libertad de contratación, con posibilidades de actuación iguales a las de una sociedad por acciones ${ }^{14}$.

De hecho, en relación con la señalada Ley de 19 de octubre de 1869, el Tribunal Supremo, en sentencia de fecha 22 de enero de 1904, ya consideraba que «la Ley de 19 de octubre de 1869 no se opone, en su artículo 2 ni en ningún otro, a que puedan ser mercantiles las sociedades cooperativas» ${ }^{15}$, con lo que daba carta de naturaleza

12 Vid GÓMEZ CALERO, en «Sobre la «mercantilidad» de las cooperativas», RDM, n. ${ }^{\circ}$ 137, Madrid, 1975, pp. 304-342, quien hace un estudio por hitos legislativos en materia de regulación de las cooperativas, hasta la publicación de la Ley General de Cooperativas de 1974.

13 La Ley de 19 de octubre de 1869, para la libre creación de sociedades anónimas y de crédito, pese a su nombre y finalidad, nombró, por primera vez, en nuestro ordenamiento jurídico, a las cooperativas, exigiendo su constitución por medio de escritura pública (art. 2), y la elaboración y publicación de un estado sobre el capital social y el número de socios (art. 4), tal y como describe MATILLA QUIZA, en «Debates Parlamentarios y Leyes sobre la Asociación de Capitales (1810-1874)», Revista de Estudios Políticos (Nueva Época), n. ${ }^{\circ}$ 93, Julio-Septiembre 1996, p. 397.

14 Vid. GUINNANE y MARTÍNEZ RODRÍGUEZ, en su trabajo «¿Fue alguna vez la cooperativa un sociedad por acciones?», Documentos de Trabajo, Asociación española de historia económica, Noviembre 2009, pp. 5, 11 y ss. En este trabajo se hace un recorrido histórico desde el Antiguo Régimen hasta el momento de la postguerra civil española, analizando los distintos períodos históricos desde el nacimiento de las cooperativas, en su relación con la normativa específica de las sociedades anónimas en España.

15 Cita tomada de GÓMEZ CALERO, en "Sobre la "mercantilidad"...», op. cit. 1975, pp. 308-309. La misma cita la recoge MUNDO GUINOT, en su Tesis doctoral «Naturaleza, Régimen Jurídico y Actividades de las Sociedades Cooperativas de Transporte de Mercancías por Carretera», Universitat Jaume I de Castellón, Castellón de la Plana, 2011, p. 38, http://repodoc.uji.es/jspui/bitstream/10803/4851/1/mmundo.pdf 
a la concepción doctrinal de que las cooperativas pueden ser sociedades mercantiles y regirse, por tanto, por sus normas especiales.

\subsection{Desde la publicación del Código de comercio de 1885}

Con la publicación del Código de Comercio de 1885 la visión del legislador nacional sobre las cooperativas está lejos de considerarlas como sociedades de carácter mercantil. Ya en el preámbulo del Código, cuando habla de las tipologías societarias que regula para calificarlas como mercantiles, se señala que «...comprende el Proyecto adjunto todas las sociedades que bien por su naturaleza, bien por la indole de sus operaciones, se consideran como mercantiles, no habiendo atribuido este carácter a las asociaciones mutuas porque falta en ellas el espíritu de especulación que es incompatible con estas sociedades, ni las cooperativas, porque obedecen, ante todo, a la tendencia manifestada en las poblaciones fabriles de nuestro país, y principalmente en las de Alemania, Inglaterra y Francia, de asociarse los obreros con el único fin de mejorar la condición de cada uno, facilitándoles los medios de trabajar, de dar salida a sus productos o de obtener con baratura los artículos necesarios para su subsistencia. Y como no es el afán de lucro el que impulsa lo que se ha dado en llamar movimiento cooperativo, no pueden reputarse como mercantiles estas sociedades mientras no resulte claramente de sus Estatutos o del ejercicio habitual de algunos actos de comercio que merecen aquella denominación».

Con la declaración de intenciones del Legislador manifestada en el Preámbulo del Código de comercio, siendo consecuente con el criterio expresado en torno a las mutuas y cooperativas, en la parte dispositiva, en el artículo 124, se señala que «...las cooperativas de producción, de crédito o de consumo, solo se considerarán mercantiles y quedarán sujetas a las disposiciones de este Código cuando se dedicaren a actos de comercio extraños a la mutualidad o se convirtieren en sociedades a prima fija», dejando, pues, al margen del ámbito mercantil lo que se entendía que debía ser, en esencia, una cooperativa, y admitiendo, por excepción, la mercantilidad de ciertas cooperativas que tienen una actividad distinta a la que le es propia.

La doctrina mayoritaria de la época (Abella, Carreras González, Romero Girón, Blanco Constans), ante tal disposición y manifestación de interés dados por el Legislador, entendiendo que la base mutualista de las cooperativas estaba muy asentada en tales estructuras jurídicas, abogaban por negar el carácter de sociedad mercantil a las coopera- 
tivas. En contra de aquella asentada opinión doctrinal mayoritaria de la época, LORENZO BENITO, afirmó que "las operaciones que practican estas sociedades -las cooperativas- pueden tener carácter mercantil... nuestro Código de Comercio ha debido incluirlas entre las sociedades mercantiles... realizaran otras de comercio, extrañas a la mutualidad, les habrían de ser, con doble motivo, aplicables las disposiciones del Código de comercio». En el mismo sentido GONZÁLEZ DE ECHÁVARRI ${ }^{16}$.

Después de la publicación del Código de comercio, se publica la Ley de Asociaciones de 30 de junio de 1887, comprendiendo en su ámbito objetivo de aplicación, a las cooperativas y otras asociaciones que no persigan el fin exclusivo de lucro o ganancia propio de las sociedades. El legislador vuelve a recalcar el carácter de asociación a las cooperativas. Sin embargo, en 1889 se publica el Código Civil, distinguiéndose, en su artículo 35, entre asociaciones de interés público y asociaciones de interés privado, regulándose estas últimas, como se ha indicado anteriormente, por las disposiciones relativas al contrato de sociedad, identificando, por tanto, a las asociaciones de interés privado como sociedades ${ }^{17}$, aunque de índole civil. Pero la regulación que el propio Código Civil hace de las sociedades civiles, tampoco encajaría en la literalidad de las cooperativas como sociedades que no persiguen lucro partible entre sus miembros, puesto que en el artículo 1.665, señala el ánimo de partir las ganancias entre los socios, como elemento integrante de la definición legal de sociedad: "contrato por el que dos o mas personas se obligan a poner en común dinero, bienes o industria, con ánimo de partir entre sí las ganancias». No son consideradas, por principio y salvo que la cooperativa se dedique a actos de comercio o actúe fuera del marco de la actividad mutualística, como sociedades de naturaleza mercantil.

16 Sobre la historia de la legislación nacional en torno a la mercantilidad de las cooperativas, vid. GÓMEZ CALERO, en «Sobre la «mercantilidad»...», op. cit. 1975, pp. 305 y ss. Con parecido desarrollo histórico, MORILLAS JARILLO hace una descripción de la regulación de las sociedades cooperativas en España en su artículo «El ámbito de aplicación de las leyes...», op. cit., 2002, pp. 4747-4760. Igualmente se puede consultar, para la situación del momento histórico legislativo español y europeo a GUINNANE y MARTÍNEZ RODRÍGUEZ, en «¿Fue alguna vez la cooperativa...», op. cit., 2009, pp. 15-19.

17 Vid en este sentido FAJARDO GARCÍA, en «El Derecho cooperativo en España: incidencia de la Constitución de 1978», en CIRIEC-España, n. 11, pp. 12-13. 


\subsection{Desde la publicación del Decreto-Ley de Cooperativas de 4 de julio} de 1931 y la Ley del Gobierno Militar de 1942

Con la publicación de la primera ley reguladora de las cooperativas en España, por el Decreto Ley de 4 de julio de 1931, que fue transformado en Ley el 9 de septiembre siguiente ${ }^{18}$, y su reglamento, el Decreto de 2 de octubre del mismo año, así como en la posterior Ley de Cooperación de 2 de enero de 1942 y su reglamento de 11 de noviembre de 1943, profundamente modificado por los Decretos de 24 de febrero y 16 de marzo de 1944, y el posterior de fecha 13 de agosto de 1971, se va asentando en nuestra doctrina, la idea mayoritaria de que la cooperativa es, esencialmente, una sociedad ${ }^{19}$. Menos consenso se da en la doctrina patria en torno al carácter mercantil de la cooperativa. GÓMEZ CALERO20 hace una clasificación de las corrientes doctrinales que parten de la aceptación de la cooperativa como sociedad, distinguiendo hasta en cuatro tendencias en orden a la mercantilidad o no de la cooperativa. Por un lado estarían aquellos que atribuyen la posibilidad de adquirir la cualidad de mercantil a la cooperativa, representada por autores como Gay de Montellá o Espejo de Hinojosa; otra corriente que considera a la cooperativa radicalmente incompatible con el carácter mercantil estaría representada por autores como Polo Díez, Langle, Vicent Chuliá; quienes piensan que el régimen legal es un obs-

18 Como analiza MORILLAS JARILLO, esta Ley de cooperativas, que en principio resultó «preconstitucional», no tuvo ningún engarce con la Constitución de la República Española de 9 de diciembre de 1931, donde se nombraba a esta tipología social sin asignarle un contenido mercantil, en sus artículos 46 y 47 , en el sentido de que «la legislación social de la República regulará «las instituciones de cooperación»... —así como que- La República protegerá al campesino y a este fin legislará, entre otras materias, sobre [...] cooperativas de producción y consumo», vid. "El ámbito de aplicación de las leyes...», op. cit., 2002, p. 4749.

19 GÓMEZ CALERO, en «Sobre la «mercantilidad»...», op. cit., 1975, pp. 309-311, enuncia y extracta las opiniones de autores tan relevantes como GASCÓN HERNÁNDEZ o LLUIS NAVAS, que niegan el carácter de sociedad a la cooperativa; y de entre el círculo de los mercantilistas, a VICENT CHULIÁ, quien, pese a reconocer que, jurídicamente, la cooperativa es una sociedad, en realidad, no lo es, sino que se trata de una institución sui generis, tal y como expone este autor en «Análisis crítico del nuevo Reglamento de Cooperación. (Decreto 2.396/1971 de 13 de agosto, «B.O.E.» de 9 de octubre», RDM, n. ${ }^{\circ} 125-126$, Madrid,», 1972, pp. 448 y ss. En este sentido, LANGLE afirma que «no es mercantil la sociedad que busque un incremento económico de sus socios operando sólo con ellos mismos, sin especular con el público (mutualidad), ni tampoco la organizada sin fin lucrativo, para beneficiarse los interesados mediante el ahorro de gastos que proporciona la supresión de intermediarios (cooperativa)», en "Manual de Derecho...», op. cit., 1950, p. 413.

20 GÓMEZ CALERO, en «Sobre la «mercantilidad»...», op. cit., 1975, pp. 311-317. 
táculo para la consideración de la cooperativa como sociedad mercantil, corriente doctrinal sostenida por autores como Vicente y Gella, o Garrigues; $y$, finalmente, quienes entienden que el régimen jurídico de las cooperativas se acerca al de las sociedades mercantiles, postura defendida por Guerrero de Castro, Olivencia Ruíz, Sánchez Calero, o el mismo Vicent Chuliá cuando, pese a sus opiniones en torno a la incompatibilidad de cooperativa y sociedad mercantil, afirma que debe aplicarse a aquella en determinados aspectos la normativa propia de las sociedades mercantiles, como en el tema del régimen de contabilidad, el sometimiento al, entonces, instituto de la quiebra o suspensión de pagos, la representación de los apoderados generales mercantiles, o la publicidad registral.

\subsection{Desde la publicación de la Ley General de Cooperativas de 1974}

A partir de la publicación de la Ley General de Cooperativas de 19 de diciembre de 1974, desaparece de su articulado la referencia a la ausencia del ánimo de lucro mercantil, o de cualquier otro, para la definición legal de cooperativa -art. 1-, con lo que, por un lado, las posturas doctrinales en torno a la no consideración de la cooperativa como sociedad en base al pretendido elemento esencial del ánimo de lucro pierden argumentación jurídica. Por otro lado, la ausencia del ánimo de lucro en la definición legal de cooperativa, significa que ésta deja de ser elemento esencial o definidor de cualquier cooperativa, que podría incluso perseguir un lucro puramente mercantil o comercial ${ }^{21}$. $Y$, finalmente, el hecho de que en el preámbulo de la nueva Ley de Cooperativas se haga expresa referencia al carácter empresarial de la sociedad cooperativa, como destaca GÓMEZ CALERO22, vale tanto como reconocer su lucro mercantil «intracooperativo» - el ahorro de costes en las de consumo, mayor retribución en las de producción, o la participación de los cooperativistas en los excedentes netos de la sociedad cuando tenga ganancias-.

Por otro lado, la nueva Ley General de Cooperativas de 1974 prevé el pago de intereses a aportaciones voluntarias de los socios, lo que conlleva, en cierta forma, una retribución al capital, lo que, aunque de forma un tanto forzada, acerca la cooperativa al régimen de las sociedades mercantiles de capital. Igualmente se prevé en esta Ley de 1974 
la posibilidad de que la cooperativa pueda acordar, asambleariamente, la creación de un fondo voluntario de reserva, una vez detraída la parte correspondiente a las reservas obligatorias e indisponibles, o, en su lugar, acordar el retorno cooperativo sobre ese fondo disponible, lo que conlleva la búsqueda de un beneficio social repartible, esto es, un claro ánimo de lucro, con lo que los obstáculos legales señalados en torno a las definiciones legales de sociedad del Código civil (art. 1.665) o del Código de comercio (art. 116), en torno al ánimo de lucro, desaparecen para la concepción de la cooperativa como sociedad, y luego, como señala GÓMEZ CALERO23, como «sociedad mercantil».

Igualmente la posibilidad de que la cooperativa, esencialmente las de consumo en su relación con los cooperativistas, o con terceros (por tanto, pues, fuera de su ámbito subjetivo), pueda realizar compras para revender más caro a éstos o a aquellos, y lucrarse en la reventa hace que pueda identificarse a la cooperativa como parte en un contrato de compraventa mercantil (art. 325 C. de c.), con lo que, como destaca GÓMEZ CALERO ${ }^{24}$ cuando analiza la posibilidad de que las cooperativas puedan realizar "actos de comercio extraños a la mutualidad», tal y como exige el artículo 124 del Código de Comercio para la consideración las cooperativas como sociedades de naturaleza mercantil, el hecho de que la cooperativa pueda realizar operaciones con terceros, con quienes no tiene vínculo alguno de carácter mutualístico, las englobaría dentro del requisito señalado del Código de comercio para aplicarles el calificativo de sociedades mercantiles.

Por otro lado, la Ley General de Cooperativas de 1974 viene a regular un sistema jurídico de fundación, en palabras de GÓMEZ CALERO25, "afín a las disposiciones del Código de comercio», tanto en lo referente a la necesidad del otorgamiento de escritura pública del acto fundacional, como su inscripción en un Registro público, el General de Cooperativas con carácter constitutivo para la adquisición de la capacidad jurídica por parte de la cooperativa, previa «toma de razón» en el Registro mercantil (art. 41 de la Ley de 1974), lo que no puede ser sino la previa inscripción en el Registro mercantil, lo cual no implica, por ese solo hecho, la asunción del carácter mercantil de la sociedad cooperativa, puesto que en el régimen jurídico del Registro mercantil, desde la reforma operada en el Código de comercio con la Ley 16/1973, de 21 de julio, se podían inscribir "Cualesquiera personas o entidades natu-

\footnotetext{
23 lb., , pp. 322-323.

24 Ib., 323-327.

25 lb., pp. 327-331.
} 
rales o jurídicas, públicas o privadas, aunque no se dediquen habitualmente al comercio... $»^{26}$.

Pese a que la inscripción en el Registro mercantil no le confiriera, por sí, la condición de empresario, lo cierto es que tal exigencia acerca la cooperativa al régimen de las sociedades mercantiles. No obstante, en el actual régimen jurídico nacional relativo a la Cooperativa Europea con domicilio en España, se exige, para su constitución, la inscripción en el Registro Mercantil territorial que le corresponda en función del domicilio social27, con lo que, pese a que, como hemos señalado, la mercantilidad de la inscripción en el registro mercantil no es definitoria, la exigencia actual de inscripción en el Registro Mercantil de las cooperativas europeas con domicilio en España sí que resulta un dato de interés y a considerar.

Otro dato a valorar lo dio el hecho de que en la Ley de 1974 se previera una serie de circunstancias que le son de aplicación a la cooperativa y que coinciden con el denominado "estatuto del empresario mercantil», tales como la necesidad de que en la cooperativa hubiera una llevanza de libros de contabilidad que dejarán de estar diligenciados por la Delegación Provincial de la Organización Sindical, y se legalizarán por el Juzgado competente ${ }^{28}$, con lo que se equiparan las cooperativas a las demás sociedades mercantiles en cuanto al cumplimiento de éste requisito formal.

Otra de las circunstancias que afectan a las cooperativas dentro del marco del estatuto del empresario, es su afección, en caso de insolvencia, al régimen mercantil de la suspensión de pagos o, en su caso, quiebra ${ }^{29}$. Hasta la entrada en vigor de la Ley General de Cooperativas de 1974, en caso de crisis económica, a la cooperativa se le aplicaba el instituto de insolvencia previsto para el no comerciante, esto es, la quita y espera y el concurso. El que a partir de la Ley de 1974 se le aplicara a las cooperativas el régimen de las insolvencias de los comerciantes, por sí solo, tampoco implicaba necesariamente que se debiera considerar a la cooperativa como un empresario, puesto que también se habían de acoger al instituto de la quiebra los socios colectivos en caso de insol-

26 Redacción dada al 16.5. ${ }^{\circ}$ del Código de comercio con la Ley 16/1973, de 21 de julio.

27 Artículo 3 de la Ley 3/2011, de 4 de marzo, por la que se regula la Cooperativa Europea con domicilio en España.

28 Hasta la modificación del Código de comercio con la Ley 19/1989, de 25 de julio, de Reforma parcial y adaptación de la legislación mercantil a las Directivas de la Comunidad Económica Europea en materia de Sociedades, los libros contables de los empresarios se legalizaban por los Órganos de Justicia municipal.

${ }_{29}$ Así se recoge en el artículo 46.6 Ley General de Cooperativas de 1974. 
vencia de la sociedad colectiva o la comanditaria simple, lo que no convertía, por tal motivo, al socio colectivo en empresario o comerciante. Pero el hecho de circunscribir a la cooperativa en el marco de la insolvencia empresarial, la acerca, de forma natural, a una concepción de la sociedad cooperativa, como sociedad mercantil.

Otros datos que acercan el régimen jurídico de la cooperativa dado por la Ley General de Cooperativas de 1974 al régimen mercantil, lo señala GÓMEZ CALERO30, son que el capital social de las cooperativa se regula bajo los mismos dos principios del capital propio del régimen de las sociedades anónimas, esto es, el de suscripción íntegra y desembolso mínimo - artículo 13.2-; o el hecho de que se instaure en el régimen de las cooperativas la posibilidad de existencia de asambleas generales ordinarias o extraordinarias sin previa convocatoria - artículo 24-, esto es, de carácter universal, igual que en el régimen de las sociedades anónimas; o la remisión expresa en el texto de la Ley General de Cooperativas al régimen de la entonces Ley de Sociedades anónimas de 1951 en cuanto a la posibilidad de impugnar acuerdos asamblearios —artículo 27 de la L.G.C., que se remite al artículo 70 L.S.A.-; o la imitación del régimen previsto en la Ley de Cooperativas referente a la responsabilidad de los miembros del Consejo Rector y, en su caso, del Director -artículo 35-, que lo asimila al régimen previsto por la L.S.A. y la L.S.R.L. para los miembros del órgano de administración, todas estas «incorporaciones legislativas» propias de las sociedades anónimas al régimen propio de las cooperativas las acerca a una concepción mercantil de esta tipología social.

En definitiva, son tantas las novedades que introduce la Ley General de Cooperativas de 1974 y tan cercanas al régimen de las sociedades de capital, que no parecía que se pudiera calificar, de forma gratuita o infundada a la cooperativa sino como una sociedad propiamente mercantil. Quizá en un alarde de contundencia, autores como ROMERO LÓPEZ31 ${ }^{31}$ después de analizar el nuevo régimen jurídico de las

30 Vid. GÓMEZ CALERO, en «Sobre la «mercantilidad»...», op. cit., 1975, pp. 337342.

31 Vid. ROMERO LÓPEZ, en «Algunas reflexiones de tipo económico sobre las empresas cooperativas y las sociedades anónimas en España», en Revista Agricultura y Sociedad, N. ${ }^{\circ} 11,1979$, p. 272. No obstante, para llegar a tan drástica conclusión, este autor significa y ejemplariza que "el diferente criterio de reparto del beneficio constituye en teoría una de las características estructurales que diferencian en mayor medida a las cooperativas de las sociedades anónimas... los socios de las cooperativas... reciben sus retornos... proporcionalmente a lo que podríamos llamar aportaciones de los socios al proceso productivo de la empresa... la aportación de recursos por parte de los socios al proceso productivo de la cooperativa juega un papel parecido al de una es- 
cooperativas de 1974, afirmaba que «las cooperativas, según la legislación española, funcionan de hecho como sociedades anónimas que gozan de claras ventajas fiscales, y que reparten sus beneficios proporcionalmente a las aportaciones -implícitas- de los socios al proceso productivo de la empresa».

\subsection{Publicación de la Constitución española de 1978 y la delimitación de competencias entre el Estado y las Comunidades Autónomas}

Con la publicación de la Constitución de 1978, se le otorga una protección especial a las cooperativas. El artículo 129.2 dispone que "Los poderes públicos promoverán eficazmente las diversas formas de participación en la empresa y fomentarán, mediante una legislación adecuada, las sociedades cooperativas». Como ya ha quedado expuesto anteriormente cuando señalamos el efecto de la falta de uniformidad legislativa en materia de cooperativas en el Ordenamiento Jurídico nacional, en la Constitución Española se hace una distribución de competencias legislativas en torno a determinadas materias en exclusiva para el Estado - art. 149- y las que pueden asumir, también en exclusiva, las Comunidades Autónomas - art. 148-, de tal forma que las no reservadas exclusivamente para el Estado, podrán ser asumidas por las Comunidades Autónomas - art. 149.3-. La competencia legislativa en materia mercantil, conforme a lo dispuesto en el artículo 149.1-6. ${ }^{\circ}$, es exclusivas del Estado, y, sin embargo, como hemos expuesto anteriormente, se fueron dictando distintas leyes orgánicas, y por tanto estatales, aprobando los estatutos de autonomía de diversas comunidades autónomas ${ }^{32}$, donde se recogían las competencias exclu-

pecie de aportación implícita al capital social de la cooperativa... las ganancias se reparten proporcionalmente a las aportaciones implícitas en el caso de las cooperativas y proporcionalmente a las aportaciones propiamente dichas en el caso de las sociedades anónimas».

32 La Ley Orgánica 3/1979, de 18 de diciembre, Estatuto de Autonomía del País Vasco, en su artículo 10.23; La Ley Orgánica 4/1979, de 18 de diciembre, Estatuto de Autonomía de Cataluña, en su artículo 9; La Ley Orgánica 6/1981, de 30 de diciembre, de Estatuto de Autonomía para Andalucía, en su artículo 13.20; la Ley Orgánica 77/1981, de 30 de diciembre, Estatuto de Autonomía para Asturias —-denominado, posteriormente, del Principado de Asturias por la Ley Orgánica 1/1999, de 5 de enero-, en su artículo 10.1.27; la Ley Orgánica 8/1981, de 30 de diciembre, de Estatuto de Autonomía para Cantabria, en su artículo 24.26; la Ley Orgánica 4/1982, de 9 de junio, Estatuto de Autonomía de Murcia, en su artículo 10.23;la Ley Orgánica 5/1982, de 1 de julio, de Estatuto de Autonomía de la Comunidad Valenciana, en su artículo 31.21, ésta «respetando la legislación mercantil»; la Ley Orgánica 8/1982, de 10 de agosto, Esta- 
sivas de la Comunidad en materia de cooperativas. En el desarrollo de las competencias exclusivas asumidas por las distintas comunidades autónomas se fueron publicando diversas leyes sustantivas sobre cooperativas, y la primera fue la de Euskadi, la Ley 1/1982, de 11 de febrero, sobre Cooperativas del País Vasco.

Sin volver a lo expuesto sobre la falta de unidad legislativa en materia de cooperativas en España, señalar, solo, que la sentencia del Tribunal Constitucional n. ${ }^{\circ}$ 72/1983, de 29 de julio, vino a ignorar la naturaleza mercantil de la cooperativa lo que permitió la legislación autonómica sustantiva de esta estructura societaria que, pese a desarrollar una actividad económica y profesional, no la entendía comprendida en el ámbito de las competencias legislativas exclusivas del Estado.

Las comunidades autónomas que previeron en sus respectivos Estatutos de Autonomía la competencia exclusiva en materia de cooperativas desarrollaron, paulatinamente, sus primeras normas sobre la materia. Y, finalmente fue el Estado, por medio de la Ley Orgánica 9/1992, de 23 de diciembre, de Transferencia de competencias a Comunidades Autónomas que accedieron a la autonomía por la vía del artículo 143 de la Constitución, quien traspasó a todas las comunidades autónomas las competencias legislativas en materia de cooperativas.

Esta sola circunstancia hace que no resulte fácil la calificación de las cooperativas como sociedades de naturaleza mercantil, pues, en ese caso, el desarrollo legislativo sobre las mismas le debería haber correspondido, con carácter de exclusividad, al Estado (art. 149.1-6. ${ }^{\circ}$ C.E.). No obstante, las distintas normas autonómicas de cooperativas, fueron, como anteriormente la Ley General de Cooperativas de 1974, acercándose, cada vez más, a la legislación societaria mercantil33, aunque

tuto de Autonomía de Aragón, en su artículo 25.1.23; la Ley Orgánica 9/1982, de 10 de agosto, Estatuto de Autonomía de Castilla-La Mancha, en su artículo 31.22; la Ley Orgánica 13/1982, de 10 de agosto, de Reintegración y Amejoramiento del Régimen Foral de Navarra, en su artículo 44.27; la Ley Orgánica 1/1983, de 25 de febrero, Estatuto de Autonomía de Extremadura, en su artículo 7.23; la Ley Orgánica 2/1983, de 25 de febrero, Estatuto de Autonomía de las Illes Balears, en su artículo 30.30; la Ley 3/1983, de 25 de febrero, Estatuto de Autonomía de la Comunidad de Madrid, en su artículo 26.1.4; la Ley 4/1983, de 25 de febrero, Estatuto de Autonomía de Castilla León, en su artículo 70.28 .

33 De hecho, aunque en la primera Ley Vasca de Cooperativas, la 1/1982, de 11 de febrero, viene a distanciarse del modelo societario mercantil en cuanto a la fundación de la cooperativa, pues la exime de la necesidad del otorgamiento de la escritura pública — criterio rectificado en la posterior Ley de cooperativas vascas de 1993-, lo cierto es que en aspectos sustantivos como los libros y la contabilidad, lo remite el legislador vasco a la Legislación Común, que es la mercantil, puesto que la contabilidad sólo es exigible al empresario. Igualmente el legislador del País Vasco hace una declara- 
manifestando lo contrario, esto es, enunciando formalmente su distanciamiento respecto a la legislación mercantil, pero imitando y acercándose en su contenido, cada vez más, al modelo de desarrollo legislativo de las sociedades de éste ámbito. La razón no es complicada de entender puesto que se trata de una legislación de ámbito autonómico en un país que asigna la competencia exclusiva al Estado en materia mercantil. Afirmar lo contrario supondría la deslegitimación de la fuente material que emite la norma autonómica. Aunque esta paradoja resulta complicada de superar en las normas autonómicas que se publican con anterioridad a la Sentencia del Tribunal Constitucional número 72/1983, que resolvía la cuestión de inconstitucionalidad de la primera ley vasca de cooperativas, admitiendo la competencia exclusiva autonómica que así lo haya recogido en su estatuto de autonomía, por lo que tienen que afianzar el distanciamiento de la estructura cooperativa del ámbito mercantil. El resto de normas autonómicas que se publican con posterioridad a la Sentencia del Constitucional ya no necesitan de forzar argumentos que les legitime su competencia ${ }^{34}$.

ción de intenciones en el Preámbulo, afirmando «...la ruptura del principio mutualista, que en cierta medida flotaba en el concepto de cooperativa...», lo cual hace casar a las cooperativas en la tipificación del artículo 124 del Código de Comercio. En cambio, la Ley 4/1983, de 9 de marzo, de Cooperativas de Cataluña, y su posterior Texto Refundido por el Decreto Legislativo 1/1992, de 10 de febrero, en palabras de BORJABAD GONZALO, "ha venido a extender sobre las Cooperativas catalanas la antigua discusión sobre su no mercantilidad, cuando hoy dábamos por zanjada tal cuestión en favor de esta calificación , y se llama la atención sobre este asunto... por la calificación de falta muy grave, en el artículo 108.5.f, que puede tener como consecuencia la descalificación de la Cooperativa, al hecho de «encubrir, bajo la fórmula de la sociedad cooperativa, finalidades propias de las sociedades mercantiles»».

34 Las leyes autonómicas sobre cooperativas que se publicaron tras la Sentencia del Tribunal Constitucional 72/1983, que resolvía la posible inconstitucionalidad de la primera Ley vasca legitimando la competencia autonómica sobre la materia, hizo que el correspondiente legislador autonómico no pretendiera más justificación y argumentación para distinguir a la cooperativa de las sociedades mercantiles. De hecho, la Ley 2/1985, de 2 de mayo, de Sociedades Cooperativas Andaluzas, en su exposición de motivos, después de distinguir a las cooperativas de las sociedades mercantiles, con quien compite, viene a recalcar para las cooperativas «...la exigencia de eficacia en la gestión y criterios empresariales de funcionamiento....», así como, al marcar el ámbito subjetivo de aplicación de la Ley, "...ha de abarcar solamente a aquellas sociedades cooperativas que desarrollen su actividad societaria en Andalucía, sin perjuicio de las habituales operaciones de tráfico comercial y mercantil», y en cuanto a su estructura financiera, apuesta el Legislador andaluz por incrementar "los porcentajes de excedentes que se han de destinar al Fondo de Reserva Obligatorio, al objeto de lograr una progresiva capitalización que permita una estructura empresarial fuerte», apostando por «una la regulación de las operaciones con terceros de manera más libre», abandonando, pues, el carácter mutualista de la sociedad. Se pretende la mercantilización de una sociedad que, 
En cualquier caso, la legislación autonómica toma el modelo de las sociedades de capital para el desarrollo normativo de las cooperativas, y no es de extrañar, puesto que el modelo societario mercantil es el más desarrollado tanto a nivel legislativo, como doctrinal y casuísticamente más experimentado, con lo que el desarrollo de la legislación cooperativa en clara tendencia a la mercantilidad, entendida como profesionalización dentro del mercado, es, no solo lógico, sino inevitable. Si la cooperativa opera y se desarrolla en el mercado, las respuestas legislativas y organizativas de los operadores en tal mercado, por «contaminación», en palabras de DIVAR ${ }^{35}$, hace que se extiendan a las cooperativas. Se produce, como señala PANIAGUA ZURERA, un acercamiento de la concepción de la cooperativa bajo parámetros "social o clasista» propios de los modelos jurídicos del ámbito mediterráneo, muy influido por los principios y valores dictados por la A.C.I., a parámetros o concepciones de la cooperativa de carácter «economicista o funcional» propios de un modelo jurídico de cooperativas como el alemán, que se aproxima al régimen de los tipos sociales legales capitalistas ${ }^{36}$.

\subsection{Desde la publicación de la Ley General de Cooperativas de 1987}

La Ley 3/1987, de 3 de abril, General de Cooperativas, viene a derogar a la anterior de 19 de diciembre de 1974, que tenía un ámbito

por ser competencia exclusiva de la Comunidad Autónoma, no puede ser mercantil. La Ley $1 / 1985$, de 25 de octubre, de Cooperativas de la Comunidad Valenciana, parte de la premisa enunciada en su Exposición de Motivos, de que «el problema jurídico formal de la delimitación de su competencia legislativa, en buena medida resuelto por la jurisprudencia del Tribunal Constitucional», lo que hace que, sin recato afirme "el carácter específico y unitario de la cooperativa como agrupación de personas y como empresa... los retos del mercado que exigen la configuración de la cooperativa como una auténtica empresa e incorpora las técnicas del moderno Derecho de sociedades».

35 DIVAR propone una labor de «contaminación» del cooperativismo hacia las empresas capitalistas, que hará que, dado que toda empresa concurre en el mercado liberal, en el capitalismo "civilizado» y participativo, y solo la competitiva triunfará, a fuerza de ser competitivas las cooperativas, las sociedades capitalistas irán incorporando parámetros de actuación y esquemas estructurales propios de las cooperativas, con lo que, se tenderá a una democratización del mercado y de la actividad económica, por la paulatina democratización de las sociedades capitalistas. Sin embargo, si las cooperativas tienen que contaminar a las sociedades mercantiles o de capital, éstas también lo hacen ya respecto a las cooperativas. Vid. DIVAR en "Las Cooperativas: una alternativa económica», Edit. Dykinson, Madrid, 2011, p. 51.

36 PANIAGUA ZURERA describe los dos modelos de marco jurídico de las cooperativas, entrando examinando al clasista francés, y al economicista alemán, en «La sociedad-empresa cooperativa...», op. cit., 2013, pp. 176 a 180. 
de aplicación territorial de todo el Estado. Pero cuando se publica la de 1987 ya se ha producido la falla de la unicidad legislativa nacional con la publicación de las leyes autonómicas sobre cooperativas vasca, catalana, andaluza y valenciana.

Su ámbito de aplicación, aún, es relativamente relevante ${ }^{37}$, puesto que el Estado de las Autonomías aún no ha sido plenamente desarrollado, y territorialmente, normas autonómicas sustantivas en materia cooperativa, como hemos indicado, solo existen cuatro. No obstante, como señala PAZ CANALEJO38, la Ley 3/1987 viene a constituir "pronunciamientos de alcance y carácter mercantil tanto la supresión de la toma de razón... en el Registro Mercantil... como la remisión al Código de comercio en materia de contabilidad..., así como la regulación del proceso de transformación de determinadas Sociedades mercantiles en Cooperativas de Trabajo Asociado... Pues bien, en todos estos casos hay que recordar que, por el carácter mercantil de dicha legislación, la normativa mencionada ha de aplicarse con carácter general, uniforme e incondicionado en todo el territorio españo/».

El nombramiento y separación de miembros del Consejo Rector; la posibilidad de impugnación de acuerdos del órgano de administración; el sometimiento al régimen de auditoría; la flexibilización de la transmisión de las aportaciones entre ascendientes, descendientes y cónyuge; la determinación de los requisitos formales para modificaciones estatutarias conforme al modelo de sociedad anónima; la previsión de reactivación de la sociedad; la posibilidad de que exista un Letrado Asesor; o el desembolso mínimo parcial del veinticinco por ciento del capital suscrito, son, todos ellos, temas que la nueva Ley General de Cooperativas viene a imitar del régimen mercantil de las sociedades de capital. Es tan acusado el modelo de sociedad mercantil en el nuevo régimen legal que presenta la Ley de 1987, que, autores como SANZ JARQUE ${ }^{39}$ afirma que «la acción empresarial de la Cooperativa es (sic.), constituye, el objeto social de la misma, que se extiende conjunta e indivisiblemente no solo a la consecución de los fines em-

37 Vid., PAZ CANALEJO, en «Principales innovaciones de la Ley 3/1987, General de Cooperativas», REVESCO N. ${ }^{\circ} 54$ y 55, Madrid 1986/87, p. 20, que señala que "discrepo de quienes se han apresurado a afirmare que la nueva Ley sólo tiene «rango (sic.) de Ley supletoria de las Autonómicas.», o que "su carácter general es casi simbólico, porque sólo tiene carácter de Derecho Supletorio respecto al Derecho de las Comunidades Autónomas...»

38 Ibidem, pp. 19-20.

39 Vid. SANZ JARQUE., en «Derechos y obligaciones de los socios de las Cooperativas. Conforme a la Ley 3/1987, de 2 de abril, General de Cooperativas», REVESCO, n. ${ }^{\circ}$ 55-56, Madrid 1986/87, pp. 47 y 48. 
presariales inmediatos para satisfacer las necesidades de los socios... sino... también a la gestión, organización y funcionamiento de gobierno de la misma», aunque, finalmente, este autor apuesta por la aplicación a las cooperativas el Ilamado Derecho cooperativo, diferente y distinto del Derecho mercantil, tal y como enuncia la Sentencia del Tribunal Constitucional n. ${ }^{\circ}$ 72/1983, fundamentando tal conclusión en la definición que este autor da de las cooperativas conforme a la ley de 1987, cuando afirma que éstas deben estar al servicio inmediato de los socios y de la Comunidad e imputando a aquellos los resultados económicos, una vez atendidos los fondos comunitarios, en función de la actividad cooperativa que realizan, lo que «les diferencian esencialmente de los demás modelos o sistemas societarios-empresariales existentes» ${ }^{40}$. Abundando el autor, con base a lo dispuesto en el art. 85 de la Ley 3/1987, que «los resultados empresariales... se imputan a los socios no en proporción al capital sino en función a la actividad cooperativizada que realizan». En el mismo sentido, SABATÉ, SABI y SALDRIGUES ${ }^{41}$, señalan que la diferencia entre entidades cooperativas y las mercantiles "se basa fundamentalmente en dos aspectos. Uno de ellos, es el referente a la representación, personalista, cada persona un voto, en las entidades cooperativas, y capitalista, en función del porcentaje de capital social, en las entidades mercantiles. Otro, el derivado de la distribución de los excedentes, en proporción a la actividad cooperativizada en las cooperativas y en proporción al capital social en las sociedades mercantiles».

Respecto al primer argumento, señalar, en primer lugar, la indebida identificación de las sociedades capitalistas con las sociedades mercantiles. Aunque con escasa implantación en la práctica societaria, hay sociedades mercantiles no capitalistas como las colectivas y las comanditarias simples. En segundo lugar, la propia Ley General de Cooperativas, exige el voto ponderado de las distintas clases de so$\operatorname{cios}^{42}$, y prevé la posibilidad estatutaria de voto en función de la aportación para las sociedades cooperativas mixtas ${ }^{43}$, con lo que no es correcta la afirmación de que una persona es un voto. Depende de qué clase de socio sea quien lo emita y de la clase de cooperativa que con-

40 Ibidem, p. 50.

41 Vid. SABATÉ, SABI y SALADRIGUES, en «Cooperativas versus sociedades mercantiles. El sector frutero en Lleida» CIRIEC-España, n. ${ }^{\circ}$ 34, abril 2000, p. 58.

42 Los asociados pueden alcanzar hasta el treinta y tres por ciento de aportaciones al capital y su voto no puede superar el veinte por ciento del total (arts. 40.3 y 41.1 L 3/1987, de 2 de abril, General de Cooperativas).

43 Art. 107.1 L.C. 
templemos. El hecho de que en las sociedades mercantiles capitalistas se tenga un criterio de decisión democrático sobre el capital, y que las cooperativas lo tengan en función de la clase de socios no excluye, por sí, a éstas del carácter mercantil. Quizá sí del carácter puramente capitalista, pero no mercantil.

$Y$, por otro lado, respecto al reparto del beneficio en función de la realización de la actividad cooperativizada como determinante de la exclusión de la cooperativa como sociedad mercantil, consideramos que tal argumento no puede ser entendido como determinante para excluir la mercantilidad de éstas sociedades, puesto que tal circunstancia sucede, igualmente, en el ámbito puramente mercantil, regulado en el Código de comercio, respecto a la participación que ha de asignarse, en caso de que no estuviera expresamente determinada en la escritura de constitución, al socio industrial en las sociedades colectivas (art. 140 C. de c.), y, por extensión, en las comanditarias simples (art. 148 C. de c.). El socio industrial de las sociedades mercantiles personalistas no es beneficiado en base a su participación en el capital, puesto que no aporta más que su trabajo, y sin embargo, tal circunstancia no aleja a las sociedades colectivas de su carácter mercantil, que podría ser su objeto, pero no la determinación del reparto de beneficios. E, igualmente, el hecho de que la imputación de los beneficios sociales no sea proporcional a una participación en el capital y ello implique la descalificación del sujeto que los genera como empresario y, por tanto, ámbito subjetivo del Derecho mercantil, podría asimilarse a la titularidad de los beneficios que el empresario individual pudiera conseguir con su actividad profesional por el hecho de estar casado o casada bajo el régimen económico matrimonial de gananciales o bienes comunes. El patrimonio (los bienes y derechos) que el empresario individual obtenga con su actividad privativa, pese a que queden afectos a la propia actividad (art. 6 C. de c), en cuanto a la imputación del beneficio, o la determinación de la propiedad de los mismos, el cincuenta por ciento de tales bienes le corresponderán, llegado el momento de la disolución de la sociedad de gananciales, al cónyuge del empresario, quien ni aporta nada de capital al desarrollo de la actividad, ni participa en la misma, y ello no descalifica a quien lo ha generado, como sujeto propio del Derecho mercantil.

\subsection{Desde la publicación de la Ley (estatal) de Cooperativas de 1999}

Cuando se publica la Ley 27/1999, de 16 de julio, de Cooperativas, ya se han desarrollado más de la mitad de las legislaciones sustantivas 
autonómicas sobre cooperativas ${ }^{44}$; ya se ha producido el traspaso de competencias del Estado a todas las Comunidades Autónomas; ya se ha publicado la Ley Orgánica 9/1992, de 23 de diciembre, de Transferencia de competencias a Comunidades Autónomas que accedieron a la autonomía por la vía del artículo 143 de la Constitución. Por tanto, la Ley estatal se publica para el ámbito de aplicación territorial de aquellas cooperativas que tengan un ámbito territorial de actuación principal en varios territorios autonómicos o que tengan su domicilio social en las ciudades autónomas de Ceuta o Melilla (art. 2 Ley 27/1999), o para aquellas comunidades que no hayan desarrollado legislación autonómica propia, circunstancia que, actualmente, solo se da en la Comunidad Autónoma de Canarias, con lo cual, se ha publicado una Ley de ámbito supra-autonómico, pero que, en la práctica, tiene uno de los menores ámbitos de aplicación territorial del Estado45. La nueva Ley de ámbito estatal (residual), sin ambages, habla del carácter empresarial que requiere el régimen jurídico de las cooperativas, significando en la Exposición de Motivos de la Ley que «un objetivo prioritario es reforzar la consolidación empresarial de la cooperativa, para lo que ha sido preciso flexibilizar su régimen económico y societario y acoger novedades en materia de financiación empresarial...», y se rompe el criterio democrático de un socio, un voto (lo cual, entiendo, no es significativo para la calificación del sujeto que realiza la actividad profesional como de empresario o no) ${ }^{46}$, puesto que «se permite que los Estatutos con-

44 Ya se han publicado las legislaciones autonómicas en materia de cooperativa de las Comunidades Autónomas de Andalucía, Aragón, Cataluña, Euskadi, Extremadura, Galicia, Madrid, Navarra y Valencia, estando pendientes Asturias, Baleares, Canarias, Cantabria, Castilla-La Mancha, Castilla-León, Murcia y La Rioja.

45 En el año 2010, se inscribieron en el Registro Central de Cooperativas, un total de 25 cooperativas de todas las clases (http://www.meyss.es/series/), y solo en Andalucía, se crearon e inscribieron en el Registro autonómico, 174 cooperativas, también de todas las clases (http://www.juntadeandalucia.es/organismos/economiainnovacionyciencia/ servicios/estadisticas/detalle/12950.html). La pretendida «huida del Derecho cooperativo autonómico» hacia el estatal que vaticinó parte de la doctrina, parece que en la práctica no se ha dado, pese a que las condiciones de la enorme oferta legislativa autonómica, lejos de menguar, se ha incrementado al restar solo la Comunidad de las Islas Canarias para la publicación de su ley de sociedades cooperativas. De esta opinión era MORILLAS JARILLO, quien vaticinó la referida huida al régimen jurídico nacional en su trabajo «El ámbito de aplicación de las leyes...», op. cit., 2002, pp. 4808-4810.

46 De hecho, como señala SÁNCHEZ GONZÁLEZ, "para determinar la medida y extensión en que se atribuye al accionista el derecho de voto, las legislaciones modernas no adoptan un criterio viril (cada socio un voto), propio de las sociedades personalistas...»-el subrayado es nuestro-. El hecho de que el sistema de decisión política se fije de forma democrática no excluye la mercantilidad de la sociedad, puesto que sociedades mercantiles de naturaleza personalista (colectivas o comanditarias simples) admi- 
templen la posibilidad de establecer el voto plural ponderado para las cooperativas agrarias, de explotación comunitaria de la tierra, de servicios, del mar y de transportistas, y para el resto, únicamente para los socios que sean cooperativas, sociedades controladas por éstas o entidades públicas, si bien se establece la limitación de no poder superar los cinco votos sociales». De hecho, se produce la asunción en el denominado por algunos autores «Derecho cooperativo» de las estructuras y concepciones societarias desarrolladas para los empresarios sociales ${ }^{47}$. Como acreditan autores como BORJABAD GONZALO48, o PASTOR SEMPERE, "...la nueva Ley centra sus esfuerzos en reforzar la dimensión empresarial de la cooperativa para que ésta sea capaz de concurrir en el mercando con el resto de operadores económicos...», insistiendo, una vez más, respecto al objetivo de la ley, en «la finalidad de impulso de la vertiente empresarial...» de la cooperativa ${ }^{49}$.

En definitiva, si el Empresario es «la persona física o jurídica que en nombre propio y por sí o por medio de otro ejercita, organizada y profesionalmente, un actividad económica dirigida a la producción o a la mediación de bienes o de servicios para el mercado» ${ }^{50}$, o «la persona física o jurídica que por sí o por medio de delegados ejercita y desarrolla en nombre propio un actividad constitutiva de empresa, adquiriendo la titularidad de las obligaciones y derechos nacidos de esa actividad» ${ }^{51}$, y el empresario social es "la asociación voluntaria de personas que crean un fondo patrimonial común para colaborar en la explotación de una empresa, con ánimo de obtener un beneficio individual, participando en el reparto de las ganancias que se obtengan»52,

ten tal reparto de competencias entre sus socios. Vid. "La acción como fundamento de la condición de socio y como conjunto de derechos», en la obra "Las Sociedades de Capital conforme a la nueva legislación», AA.VV., Edit. Trivium, 2. ${ }^{a}$ edición, Madrid 1990, p. 237.

47 GARCÍA MAS, afirma, cuando analiza la nueva configuración del órgano de administración que introduce la Ley 27/1999, con la posibilidad de que éste sea unipersonal, que «No cabe la menor duda de que con esta modificación, se acerca esta nueva Ley de manera más clara y rotunda al Derecho Mercantil de Sociedades», en "Capítulo IV de los órganos de la Sociedad Cooperativa», en "Cooperativas. Comentarios a la Ley 27/1999, de 16 de julio, T. I», Colegios Notariales de España, Madrid 2001, p. 171.

48 Vid. BORJABAD GONZALO, en "La Sociedad Cooperativa en la Ley 27/1999», en la obra "La Sociedad Cooperativa en la Ley 27/1999», en La Sociedad Cooperativa en la ley 27/1999, de 16 de julio, de Cooperativas, AA.VV., coordinada por ALONSO ESPINOSA, Granada, 2001, pp. 7-10.

49 Vid. PASTOR SEMPERE, en «Notas en torno a las principales novedades de la Nueva Ley 27/1999, de 16 de julio, de Cooperativas», REVESCO n. ${ }^{\circ} 69,1999$, p. 152.

50 Vid. BROSETA, en «Manual de Derecho Mercantil», Edit. Tecnos, 1990, p. 56.

51 Vid. URÍA, en «Derecho Mercantil», 1985, pp. 33-34.

52 Ibidem, p. 118. 
la cooperativa que se configura en la Ley de 1999 se ajusta, plenamente, a tal concepto ${ }^{53}$. De hecho, a las cooperativas se las define, en el artículo $1 .{ }^{\circ}$, como «sociedades que... desarrollan actividades empresariales...». Otra manifestación de la exposición de motivos relevante, y su posterior desarrollo legislativo, es la creación de «... una nueva figura societaria denominada cooperativa mixta en cuya regularización coexisten elementos propios de la sociedad cooperativa y de la sociedad mercantil», que posteriormente se materializa en el art. 107 L.C. La mercantilización de las sociedades cooperativas en el marco legislativo parece, más que una tendencia, una asunción de la realidad que se contempla como necesaria.

Tras la publicación de la Ley de Cooperativas de 1999, la inmensa mayoría de los autores conceptúan a las cooperativas como «un tipo de empresario social, un ente dotado de personalidad jurídica, titular del ejercicio de una actividad económica» ${ }^{54}$.

Como ha quedado expuesto, y como señala GARCÍA-GUTIÉRREZ FERNÁNDEZ, «el carácter mercantil de la sociedad cooperativa no aparece suficientemente claro en nuestro ordenamiento jurídico... sin embargo, debe ser considerada, a todos los efectos, sociedad mercantil» 55 , abogando por la vuelta al régimen único estatal de la sociedad cooperativa y al tratamiento tributario igualitario de esta sociedad con las demás sociedades mercantiles con las que concurre en el mercado.

Y en cuanto a la doctrina patria, representada por todos los integrantes del grupo de trabajo formado en el seno de la Sección Segunda, de Derecho Mercantil, de la Comisión General de Codificación ${ }^{56}$, así como el ejecutivo anterior que aprobó el Anteproyecto de

53 En este sentido, vid. MARTÍN VIDAL, quien señala que «Ésta definición toma partido a favor de la configuración de la cooperativa como sociedad, pero no se pronuncia de manera directa sobre la mercantilidad de la cooperativa, aunque nos da algún indicio a favor de la tesis positiva la referencia a la realización de actividades empresariales, junto al desarrollo de la ley que trata de reforzar «la consolidación empresarial de la cooperativa»», en «Capítulo I. Disposiciones generales», en la obra «Cooperativas. Comentarios a la Ley 27/1999, de 16 de julio», Tomo I, AA.VV., Colegios Notariales de España, Madrid 2001, p. 34.

54 Definición, por todos, dada por MORILLAS y FELIÚ, en «Curso de cooperativas», Edit. Tecnos, 2002, p. 71.

55 Vid GARCÍA-GUTIÉRREZ FERNÁNDEZ, en «La necesidad de la consideración de la Sociedad Cooperativa como entidad mercantil para la adecuada regulación» REVESCO, n. ${ }^{\circ} 66,1998$, p. 221.

56 Por orden del Ministerio de Justicia de fecha 7 de noviembre de 2006, se encarga a la Sección Segunda, de Derecho Mercantil, de la Comisión General de Codificación, la redacción de un nuevo Código Mercantil que sustituya al vigente Código de Comercio, y cuyos trabajos debían durar cuatro años. El grupo de trabajo, presidido por Alberto 
Código Mercantil propuesto por el Ministerio de Justicia, en el Consejo de Ministros del día 30 de mayo de 2014, como se indica en la propia Exposición de Motivos referente al futuro Libro Segundo: De las Sociedades mercantiles, su declaración de intenciones es clara y contundente, "como aspecto novedoso, se ha optado por hacer expresa atribución de mercantilidad a otros tipos societarios (sociedades cooperativas, mutuas de seguros y sociedades de garantía recíproca) que dan cobertura jurídica, con estructura corporativa, a actividades empresariales organizadas con base mutualista, con independencia de que su regulación esté contenida en legislación propia fuera del Código, habida cuenta de que, tanto la especialidad tipológica, como otras consideraciones de índole competencial, no aconsejaban su inclusión en él.»57. Esta declaración de intenciones se materializa en el contenido del que se pretendía futuro precepto del artículo 211-1.1.f) del Anteproyecto de Ley de Código Mercantil, puesto que sentencia que "1. Son sociedades mercantiles las que tengan por objeto la producción o el cambio de bienes o la prestación de servicios para el mercado y las que, cualquiera que sea su objeto, adopten algunos de los siguientes tipos:... f) La sociedad cooperativa».

Esta concepción de la sociedad cooperativa como sociedad de naturaleza mercantil en la Propuesta de Código Mercantil elaborada por la Sección de Derecho Mercantil de la Comisión General de Codificación que se entregó al Ministerio de Justicia en junio de 2013, aún resultaba más contundente al prever que serían objeto de inscripción en el Registro Mercantil las sociedades cooperativas (art. 140-2 de la Propuesta58). Esta mención de la Propuesta no se recoge en el Anteproyecto, aunque en este, se menciona, en su art. 140-14.2 a las sociedades cooperativas que, de forma indeterminada, afirma que «Si mencionan el capital, las sociedades cooperativas, deberán hacer referencia al capital mínimo»,

Bercovitz, se formó con la participación de más de sesenta expertos, nombrados por órdenes ministeriales relacionadas en la Memoria de la Comisión General de Codificación año 2013, y cuyo resultado, la Propuesta, se presentó el día 19 de junio de 2013.

57 Apartado III-11 de la Exposición de Motivos del Anteproyecto de Ley de Código Mercantil, aprobado por el Consejo de Ministros de 30 de mayo de 2014, p. 25 del documento en formato pdf descargable en la página web oficial del Ministerio de Justicia, en la dirección electrónica http://www.mjusticia.gob.es/cs/Satellite/es/1215198252237/ ALegislativa_P/1288774452773/Detalle.html

58 La propuesta, que ha sido publicada por el Ministerio de Justica, puede ser consultada en formato pdf en la dirección electrónica http://www.lamoncloa.gob.es/NR/ rdonlyres/12842461-F730-40AB-8CB4-9242D1AF8553/240135/Propuesta_codigo_ mercantil.pdf 
sin especificar en qué registro hayan de inscribirse, pese a que el precepto está dentro del artículo 140 que se refiere al Registro Mercantil.

Es más, DIVAR, cuando aborda el tema de la posible y buscada cooperativización, vía estatutos sociales, de las sociedades anónimas, y tras enumerar lo que denomina "principios de la sociedad anónima», señala que la cooperativa coincide con la sociedad anónima en el principio de limitación de la responsabilidad del socio, y en el del «ámbito de la mercantilidad con independencia del objeto estatutario» 59 .

Con todas las reservas reseñadas, llegamos a la conclusión final de que las sociedades cooperativas pese a sus peculiaridades estructurales son sociedades de carácter mercantil, de estructura corporativa y de naturaleza distinta a la puramente capitalista, por lo que no hay justificación legal para la dispersión normativa estatal.

\section{Referencias bibliográficas}

Alonso EspinosA, F.J. (2001): «Prólogo» de la obra colectiva La Sociedad Cooperativa en la Ley 27/1999, de 16 de julio, de Cooperativas, AA.VV., coordinado por el mismo autor, Edit. Comares, Granada.

Borjabad Gonzalo, P. (1993): Manual de Derecho Cooperativo. General y Catalán, Edit. J.M. Bosch Editor, S.A.

Borjabad Gonzalo, P. (2001): «La Sociedad Cooperativa en la Ley 27/1999», en La Sociedad Cooperativa en la ley 27/1999, de 16 de julio, de Cooperativas, AA.VV., coordinada por ALONSO ESPINOSA, Granada, pp. 1-40.

Broseta Pont, M. (1990): Manual de Derecho Mercantil, Edit. Tecnos, Edición 8. ${ }^{a}$, Madrid.

Carreras RolG, L. (2011): "Consideraciones en torno al posible carácter mercantil de las sociedades cooperativas y acerca de las limitaciones a la realización de operaciones con terceros no socios de estas entidades», REVESCO, n. ${ }^{\circ}$ 106, Tercer Cuatrimestre 2011, pp. 55-73.

Divar Garteiz-AurrecoA, J. (2008): «La Sociedad Anónima de Estatuto Cooperativo», Boletín de la Academia Vasca de Derecho, n. ${ }^{\circ} 16$, pp. 17-24.

Divar Garteiz-AurrecoA, J. (2011): Las Cooperativas: una alternativa económica», Edit. Dykinson, Madrid.

FAJARDo GarcíA, G. (1991): «El Derecho cooperativo en España: incidencia de la Constitución de 1978», CIRIEC-España, n. ${ }^{\circ} 11$, octubre, pp. 11-35.

GarcíA-GutiérRez Fernández, C. (1998): "La necesidad de la consideración de la sociedad cooperativa como entidad mercantil para la adecuada regulación». REVESCO, n. ${ }^{\circ} 66$, pp. 207-234.

59 Vid. DIVAR GARTEIZ-AURRECOA, en «La Sociedad Anónima de Estatuto Cooperativo», Boletín de la Academia Vasca de Derecho, N. ${ }^{\circ}$ 16, 2008, p. 18. 
GARCíA JiMÉnEZ, M. (2010): «La necesaria armonización internacional del derecho cooperativo: el caso español», REVESCO, n. ${ }^{\circ} 102$, Madrid, pp. 79-108.

GarCía MAS, F.J. (2001): «Capítulo IV. De los Órganos de la Sociedad Cooperativa», en Cooperativas. Comentarios a la Ley 27/1999, de 16 de julio, T. I, Coord. José Aristónico García Sánchez, Colegios Notariales de España, Madrid, pp. 133-198.

GaRRIGUeS, J. (1943): Instituciones de Derecho Mercantil, Madrid.

GIRÓN TENA, J. (1976): Derecho de Sociedades, Tomo I, Madrid.

Gómez CAlero, J. (1975): «Sobre la «mercantilidad» de las cooperativas», RDM, n. ${ }^{\circ} 137$, Madrid, pp. 301-346.

Guinnane, T. y Martínez Rodríguez, S. (2009): «¿Fue alguna vez la cooperativa una sociedad por acciones? Leyes de negocios y de cooperativas en España (1869-1931)», Documentos de Trabajo, Asociación Española de historia económica, Noviembre, http://susanamr.zymichost.com/files/research1/ pdf1.pdf

Langle y Rubio, E. (1950): Manual de Derecho Mercantil Español, Tomo I, Edit. Bosch, Barcelona.

Llobregat Hurtado, M.L. (1992): «Régimen económico de las sociedades cooperativas», RdS, n. ${ }^{\circ} 13$, Madrid, pp. 190-228.

MARTín VIDAL, J.A. (2001): "Capítulo I. Disposiciones Generales», en la obra Cooperativas. Comentarios a la Ley 27/1999, de 16 de julio, tomo I, Colegios Notariales de España, Madrid, pp. 29-55.

Matilla Quiza, M.J. (1996): «Debates Parlamentarios y leyes sobre la asociación de capitales (1810-1874)», Revista de Estudios Políticos, n. 93, Julio-Septiembre, pp. 379-399.

MonReal ZíA, G. (2009): «Los Fueros Vascos en la Junta de Bayona de 1808», en Revista Internacional de Estudios Vascos, cuaderno 4, 2009, pp. 255 a 276

Morillas JARILLO, M.J. (2002): «El ámbito de aplicación de las leyes de sociedades cooperativas», en Derecho de sociedades. Libro Homenaje a Fernando Sánchez Calero, Vol. V, AA.VV., Edit. McGraw Hill, Madrid 2002, pp. 47454812

Morillas Jarillo, M.J. y Feliú Rey, M.I. (2002): Curso de Cooperativas, Edit. Tec-

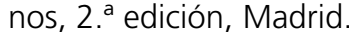

Paniagua Zurera, M. (2013): "La sociedad-empresa cooperativa en la evolución de los modelos lus Cooperativos en España», $R d S, \mathrm{n} .^{\circ}$ 40, enero-junio, pp. 159-205.

Pastor Sempere, C. (1999): "Notas en torno a las principales novedades de la Nueva Ley 27/1999, de 16 de julio, de Cooperativas», REVESCO, n. ${ }^{\circ} 69$, pp. 151-182.

Paz Canalejo, N. (1986/87): «Principales innovaciones de la Ley 3/1987, General de Cooperativas», REVESCO, n. os 54 y 55, Madrid, pp. 11-36.

ROMERO LÓPEZ, C. (1979): «Algunas reflexiones de tipo económico sobre las empresas cooperativas y las sociedades anónimas en España», Revista Agricultura y Sociedad, n. ${ }^{\circ} 11$, pp. 255-272. 
Sabaté Prats, P., Sabi Marcamo, X. y Saladrigues Solé, R. (2000): "Cooperativas versus sociedades mercantiles. El sector frutero en Lleida», CIRIEC-España, n. ${ }^{\circ} 34$, abril, pp. 51-70.

SÁnchez GonzÁlez, J.C. (1990): "La acción como fundamento de la condición de socio y como conjunto de derechos», en Las Sociedades de Capital conforme a la nueva legislación, AA.VV., Edit. Trivium, 2. a edición, Madrid, pp. 223-308.

SANZ JARQUE, J.J. (1986/87): "Derechos y obligaciones de los socios de las Cooperativas. Conforme a la Ley 3/1987, de 2 de abril, General de Cooperativas», REVESCO, n. ${ }^{\circ}$ 55-56, pp. 37-76.

URíA, R. (1985): Derecho Mercantil, décimo tercera edición, Madrid.

VICENT Chulá, F. (1972): "Análisis crítico del nuevo Reglamento de Cooperación. (Decreto 2.396/1971 de 13 de agosto, «B.O.E.» de 9 de octubre», RDM, n. ${ }^{\circ} 125-126$, Madrid, pp. 429-537.

VICENT CHULIÁ, F. (1987): "Situación actual de las cooperativas en el marco constitucional español: legalidad autonómica, estatal y fiscal», CIRIECEspaña, pp. 27-47. 